\title{
Present Status of Research and Development of Nuclear Steelmaking in Japan*
}

\section{By Keiji SHIMOKAWA**}

\section{Introduction}

The steel industry consumes an enormous amount of energy. The Japanese steel industry, being no exception, accounts for about $18 \%$ of the energy consumed in Japan as a whole. Further, about $70 \%$ of the primary energy it consumes is obtained from coal, of which about $90 \%$ is imported. Statistics show that in 1977, Japan imported about 56 million tons of coking coal at a cost of approximately $\$ 3.3$ billion.

As is generally known, the Japanese steel industry has always had the problem of procuring such huge quantities of coking coal at a stable rate. Other serious problems are price negotiations with overseas coal suppliers, transportation from collieries to Japan, and storage of coal at home.

In addition, management of the steel industry is under pressure from environmental problems caused by the consumption of such enormous quantities of coking coal. Therefore, an important subject for the Japanese steel industry is to push forward technological development in order to save coking coal or to develop steelmaking techniques which will eliminate the need of coking coal. It is towards this end and to contributing to diversification of national energy resources, that introduction of atomic energy into steelmaking processes is attempted on a grandscale.

The high-temperature gas-cooled reactor (HTGR), currently under development, is capable of supplying a large quantity of heat at high temperatures unobtainable by conventional means utilizing carbon dioxide, light water, heavy water, and fast breeder reactors. Once the utilization of the HTGR to provide process heat besides that for power generation is established, it is conceivable that this heat source will exert a great influence upon the present energy structure.

High-temperature nuclear heat can be utilized advantageously in processes to convert coal, petroleum, or natural gas into hydrogen, carbon monoxide, etc. Therefore, it is possible for the steel industry to use a large quantity of these converted gases for direct reduction or injection into blast furnaces.

In 1963, Schenck et al. of Aachen Technical College proposed the application of HTGR heat to the process of steelmaking. This proposal was the turning point from which the study of nuclear steelmaking began in many countries. In the initial stages of the study, research was carried out by British Steel Corporation, the Jürich Nuclear Research Center, and EC.
In Japan, Committee on Utilization of Nuclear Energy, the Iron and Steel Institute of Japan, was established in September, 1968. Based on the results of the investigations of this committee, Research and Development of Nuclear Steelmaking was inaugurated in July, 1973, as a national research and development program by the Agency of Industrial Science and Technology, Ministry of International Trade and Industry (MITI).

Elsewhere, the Nuclear Steelmaking Task Force was established by American Iron and Steel Institute (AISI) in 1973. In the same year, the European Nuclear Steelmaking Club (ENSEC) was established. In 1974, Arbeitsgemeinschaft Nukleare Prozesswärme (ANP) was established followed by Prototypanlage Nukleare Prozesswärme (PNP) in the Federal Republic of Germany (F.R.G.).

\section{Nuclear Steelmaking}

Atomic energy has been utilized mainly for power generation to date. However, the emergence of the HTGR in which nuclear heat is removed by helium gas coolant has opened up the possibility of utilizing the $700^{\circ}$ to $1000^{\circ} \mathrm{C}$ temperature heat as the process heat. In this temperature range, reducing gas, namely, hydrogen, or a mixture of hydrogen and carbon monoxide is efficiently produced from coal, petroleum or natural gas. In addition, ample heat in the $700^{\circ}$ to $1000^{\circ} \mathrm{C}$ temperature range, which is necessary for direct reduction of iron ore also, is obtainable quite readily from an HTGR. Thus the nuclear heat available from the HTGR can be utilized both in the production of reducing gas and in the reduction of iron ore.

Conventional techniques to convert petroleum or natural gas into reducing gas have already been established. Likewise, techniques for the direct reduction of iron ore have been established such that commercial scale shaft furnaces producing 1000 to $1200 \mathrm{t} /$ day of reduced iron are already in operation in many parts of the world. However, it is necessary to carry out research and development in nuclear steelmaking to connect these shaft furnaces to the reactors. The extensive engineering technology and expertise resulting from these studies will lead to a safe, compatible and economical nuclear steelmaking system.

The tremendous amount of development cost accompanying this research and development makes it difficult for a private enterprise or a single industry

* Originally published in Bull. Japan Inst. Metals, 17 (1977), 231, in Japanese. English version received September 8, 1978.

** Managing Director, Engineering Research Association of Nuclear Steelmaking, Otemachi, Chiyoda-ku, Tokyo 100. 
to launch such a project without the support of a more influential organization. It is regarded as being timely, therefore, that nuclear steelmaking was taken up in Japan by the Agency of Industrial Science and Technology of MITI, as the subject of a national research and development project.

The pattern of nuclear steelmaking processes varies with the selection of the material and process used for producing reducing gas, the selection of the type of reduction furnace, and whether intermediate heat exchangers are used or not. An additional but important factor to be determined is whether the site of the plant for producing reducing gas should be located remotely from the site of the steelmaking plant or the former should be an integral part of the latter.

Figure 1 shows concisely the nuclear steelmaking system which is being developed in Japan. In this process, the nuclear heat is transferred to the secondary helium through the medium of an intermediate heat exchanger. The primary helium, which comes out of the high-temperature gas reactor at $1000^{\circ} \mathrm{C}$ and $40 \mathrm{~atm}$, returns to the reactor at $400^{\circ} \mathrm{C}$, while the secondary helium comes out of the intermediate heat exchanger at $925^{\circ} \mathrm{C}$ and $45 \mathrm{~atm}$ and returns at $300^{\circ} \mathrm{C}$. The reducing gas heater, the steam reformer, and the steam heater are installed in parallel on the hightemperature side of the secondary helium loop, and the steam generator is located on the low-temperature side. Since Japan lacks fossil fuel, vacuum residual oil derived as a by-product of oil refining is selected as the raw material to produce reducing gas. Therefore, the major portion of the reducing gas, hydrogen and carbon monoxide, is produced by steam reformation of naphtha and gasification of pitch that is obtained by the cracking of vacuum residual oil by steam. The reducing gas is heated to $800^{\circ} \sim 850^{\circ} \mathrm{C}$ in the reducing gas heater and then directed into the shaft furnace. As shown in Fig. 1, the top gas of the shaft furnace is recycled in a closed system after dust elimination and other treatments.

Figure 1 also shows an integrated system in which both the reactor and the steelmaking plant are located on the same site. Whereas, Fig. 2 is a schematic diagram of a non-integrated system drawn by

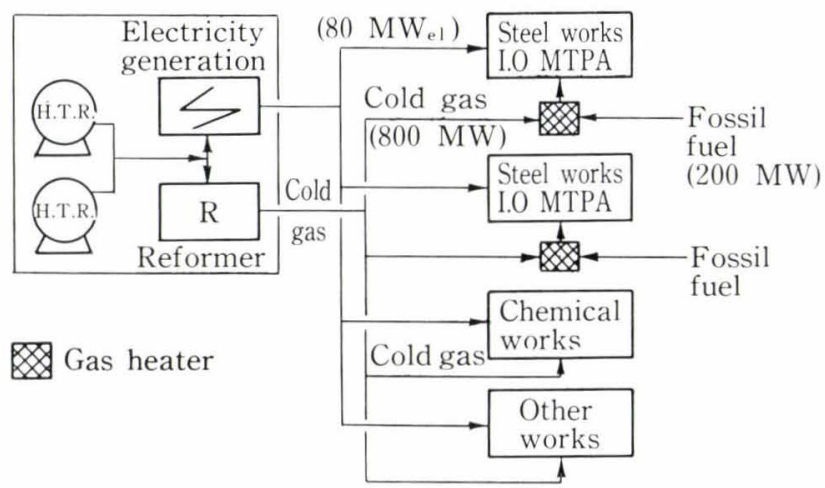

Fig. 2. A nuclear reactor gas-making and electricity generating complex serving various steelworks and other industries (ENSEC)

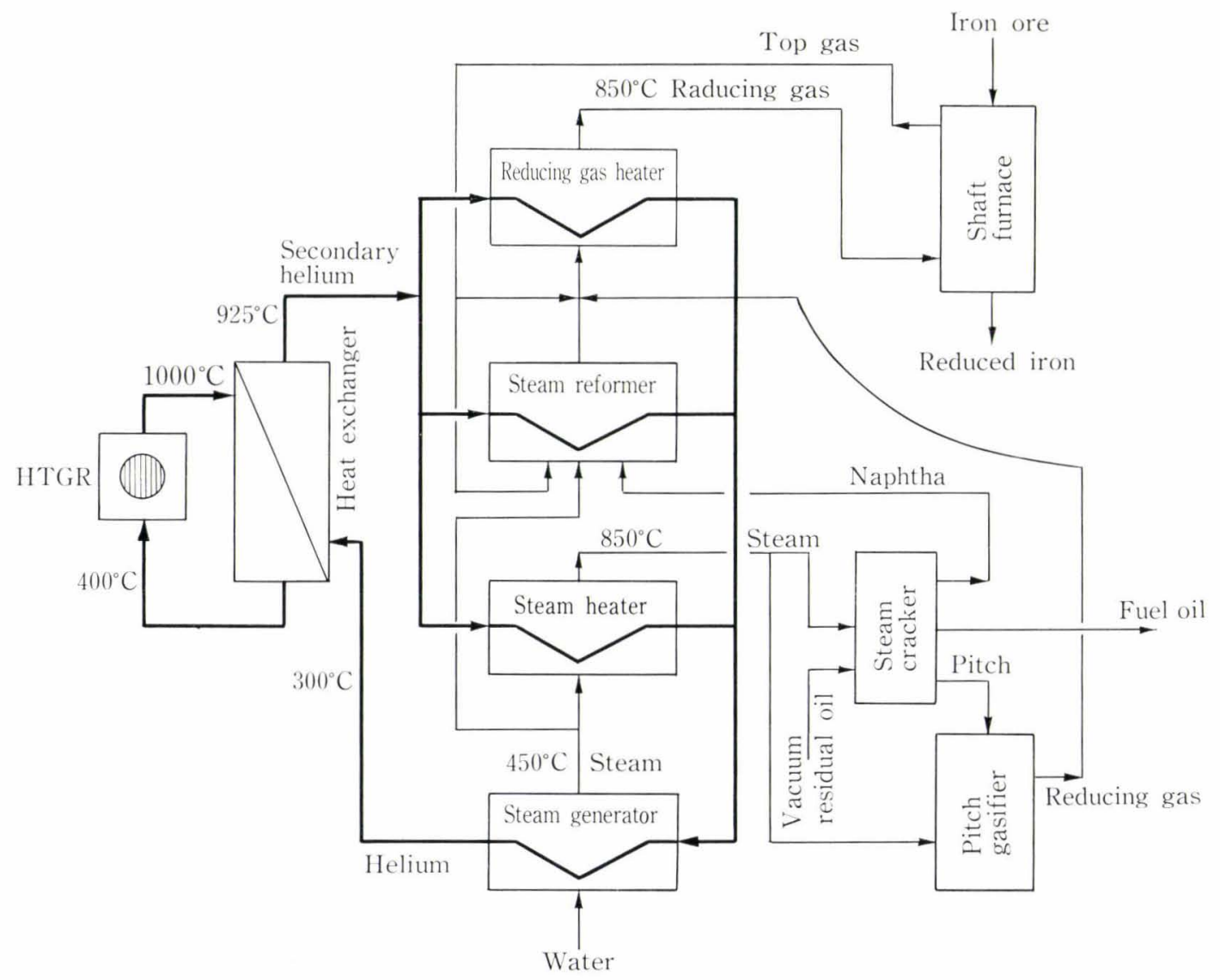

Fig. 1. Nuclear steelmaking process diagram (Japan) 
ENSEC $^{\mathbf{1})}$ where the reducing gas is piped out at a low temperature. This gas is supplied not only to the steelmaking plant but also to chemical and other plants after being heated with fossil fuels. An intermediate heat exchanger is not used in this system.

AISI is considering that the use of natural gas and fuel coal as the material for producing reducing gas and has formulated a plan for a metallurgical-chemical complex based on a Very High Temperature Gas Cooled Reactor (VHTR) system as shown in Fig. $3 .^{2)}$ Because of absence of intermediate heat exchanger, this plan is similar to that presented in Fig. 2. It is proposed that the natural gas be replaced by SNG in the reforming unit.

The PNP project is furthering the research to gasify bituminous and brown coals by nuclear heat. The PNP position is that this research is not solely for the purpose of nuclear steelmaking but is intended for both industrial and household uses. Accordingly, the steelmaking industry would be merely one of the consumers of the gasified bituminous or brown coal. Figure $4^{3}$ shows the PNP process of gasifying bituminous coal. Heat transferred via an intermediate heat exchanger to secondary helium is used for the gasifying reaction.

The process for the hydro-gasification of brown coal is presented in Fig. 5.4) In this process, helium gas at $950^{\circ} \mathrm{C}$ from the HTGR is directed to a steam reformer. The hydrogen gas obtained through the steam reformer and shift converter is fed into the brown coal gasifying unit. Part of the methane obtained in treating crude gas is sent into the steam reformer.

The processes to utilize nuclear energy as process heat elaborated above show that each reflects the particular conditions of the respective countries.

\section{High-temperature Gas-cooled Reactor (HTGR)}

An HTGR can supply a large quantity of high- temperature heat suitable for steel and chemical industries which are intensive energy consumers. The nuclear fuel used in these reactors is a coatedparticle type consisting of a number of particles, approximately $1 \mathrm{~mm}$ diameter, dispersed in a graphite matrix and molded into nuclear fuel elements. Using helium gas as the coolant, the HTGR is considered to be a clean reactor due to the low emission of fission products.

The experimental reactor, AVR (13 $\left.\mathrm{MW}_{\mathrm{el}}\right)$, installed at the Jülich Nuclear Research Center, has successfully produced heat at $950^{\circ} \mathrm{C}$.

In Japan, the Japan Atomic Energy Research Institute is promoting research and development of a multi-purpose HTGR with an output helium temperature of $1000^{\circ} \mathrm{C}$. The plans call for the construction of an experimental reactor with a thermal output of $50 \mathrm{MW}$. Figure $6^{5)}$ is a schematic diagram of this experimental reactor.

A 330 MW HTGR has been in operation at Fort St. Vrain, U.S.A. and a THTR with an almost equal capacity is to be completed in 1981 in Schmehausen, F.R.G. The helium temperature of both these reactors is about $750^{\circ} \mathrm{C}$. However, these installations are intended for electric power generation and not

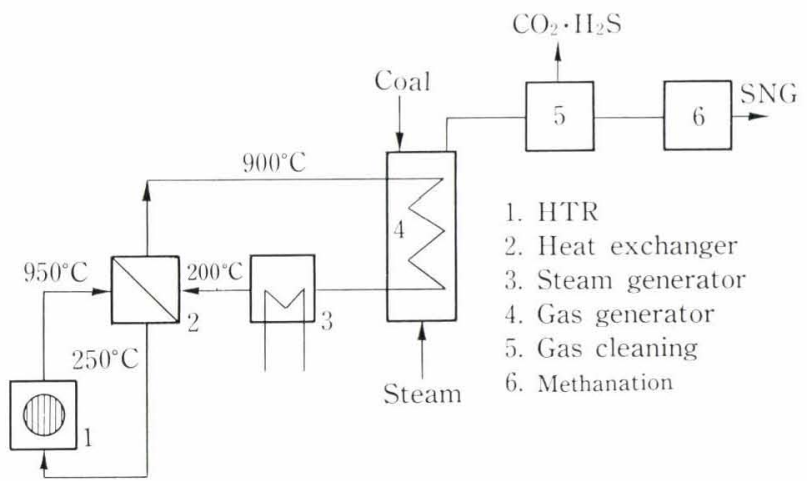

Fig. 4. Gasification of bituminous coal with steam using heat from HTRs (PNP)

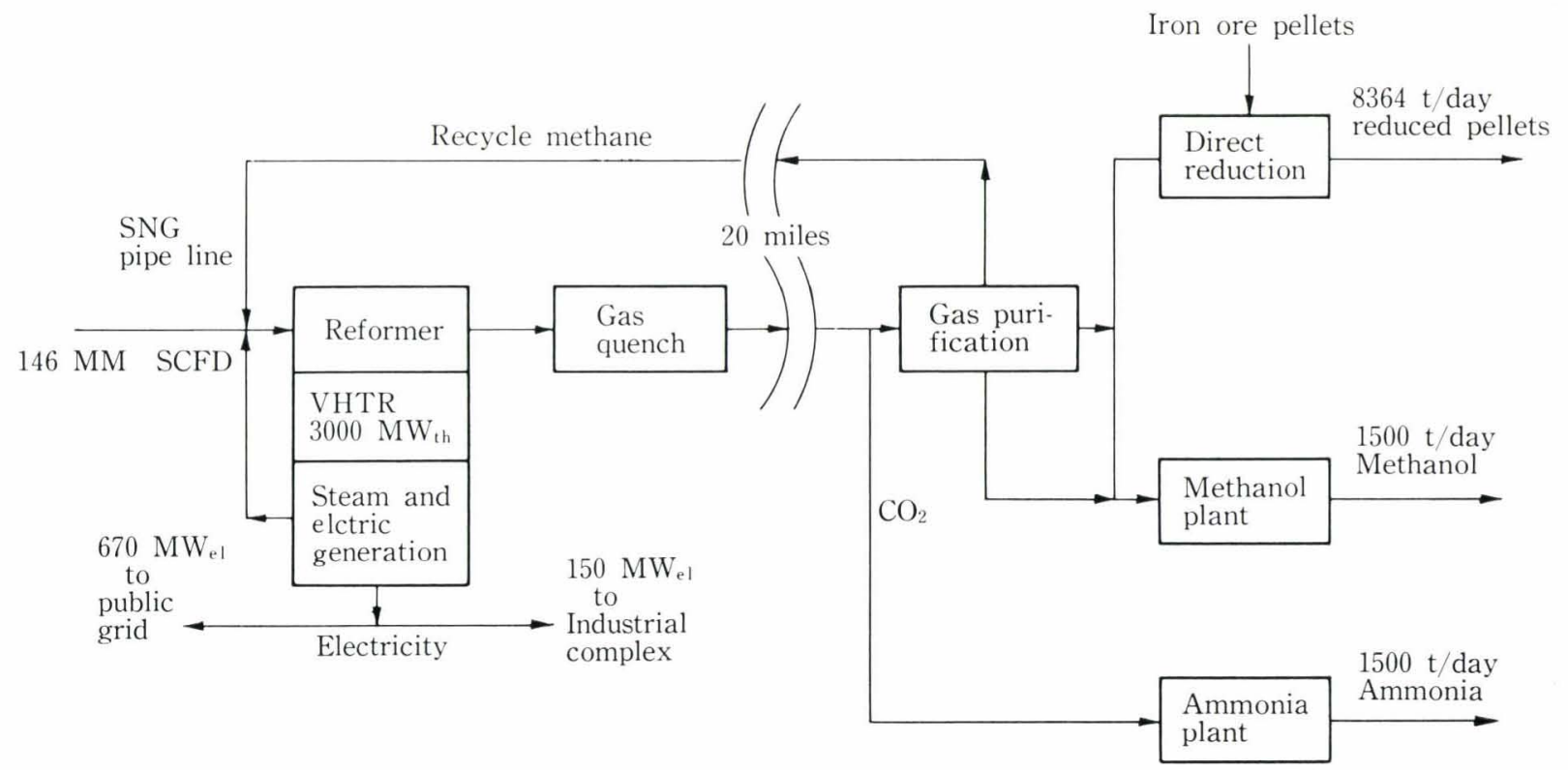

Fig. 3. A VHTR-based metallurgical-chemical complex (AISI) 


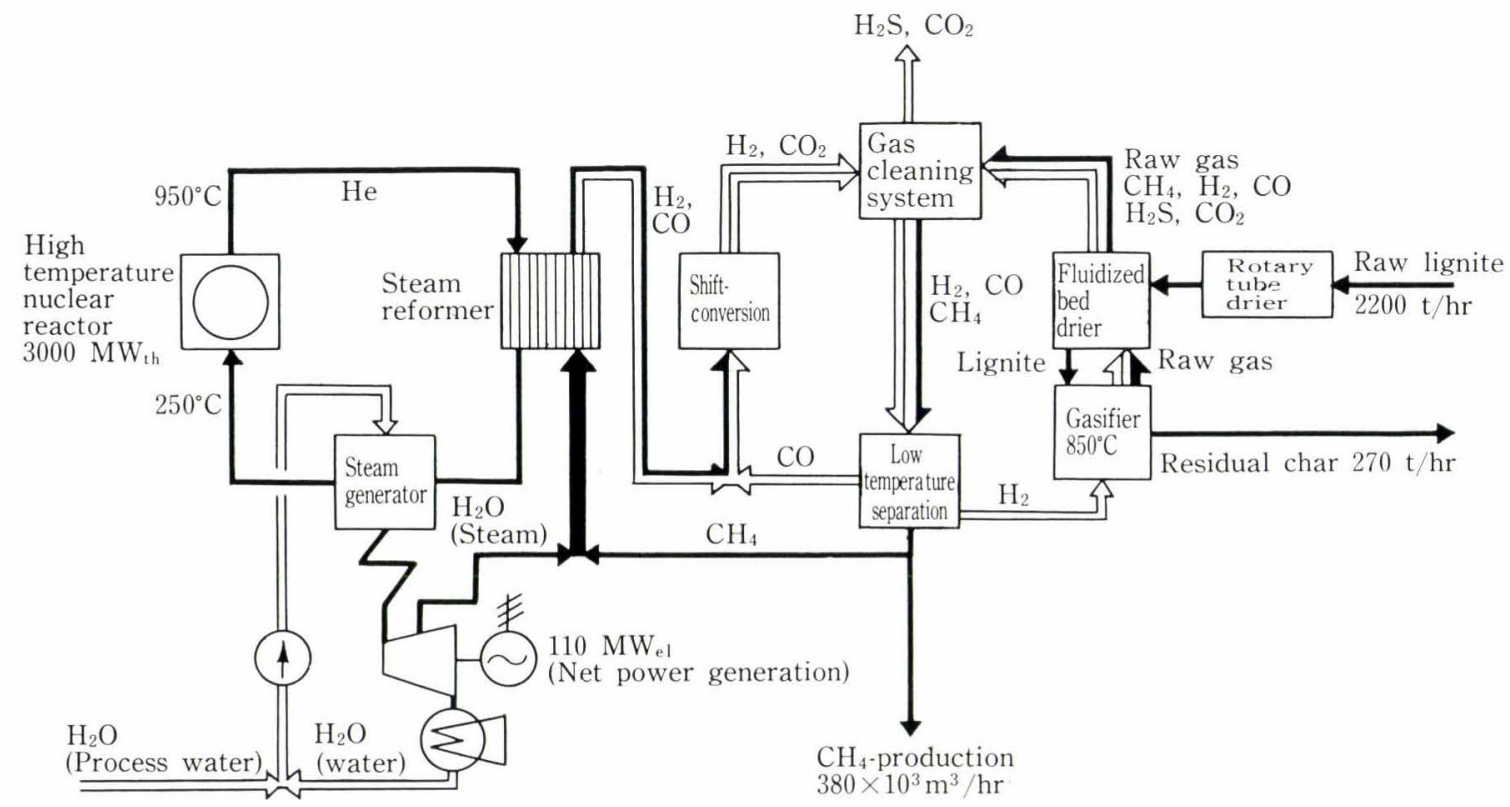

Fig. 5. Hydrogasification of lignite coupling of nuclear heat by steam reforming of methane (PNP)

for supplying process heat.

\section{Present Status of Research and Development of Nuclear Steelmaking in Japan}

Research and development of nuclear steelmaking in Japan, launched by the Agency of Industrial Science and Technology of MITI as a national research and development program, are in progress under the following subthemes:

1) High temperature heat exchanger

2) Heat resistant superalloys

3) High temperature heat insulating materials

4) Reducing gas production unit

5) Reduced iron production system

6) Total system for nuclear steelmaking

These six subsections are the principal constituents in nuclear steelmaking, and technical goals are assigned to each section.

The Engineering Research Association of Nuclear Steelmaking (ERANS) and the National Research Institute for Metals (NRIM) are executing a part of the national research and development program by the Agency of Industrial Science and Technology of MITI. More than 500 engineers and researchers are participating in this project. As shown in Table 1, about $¥ 11.8$ billion from the national budget will have been allocated by the fiscal year, 1978.

\section{High Temperature Heat Exchanger}

To achieve the necessary process temperature, the helium temperature at the reactor outlet must be increased. This condition is required to compensate for the unavoidable losses associated with the use of an intermediate heat exchanger. However, this increase results in a greater load on the reactor and a more stringent material requirement. An additional area of investigation is the high cost of the intermediate heat exchanger which in itself may negate the economical advantages of this nuclear
Table 1. National budget for FY 1973 to 1978 ( $\times 10^{6}$ Yen)

\begin{tabular}{c|rrrrrr}
\hline $\begin{array}{c}\text { Research } \\
\text { organizations }\end{array}$ & 1973 & 1974 & 1975 & 1976 & 1977 & 1978 \\
\hline ERANS* & 87 & 669 & 1755 & 3094 & 3033 & 2008 \\
NRIM $^{* *}$ & 83 & 139 & 553 & 258 & 106 & 141 \\
\hline Total & 170 & 808 & 2308 & 3352 & 3139 & 2150
\end{tabular}

* Engineering Research Association of Nuclear Steelmaking

** National Research Institute for Metals

steelmaking process. In spite of these shortcomings, for the ultimate aim of this project, that of producing reduced iron free of fission products, which is an imperative requirement for any nuclear steelmaking system, the use of intermediate heat exchangers remains unshaken.

Thus the intermediate heat exchangers will have to operate at about $1000^{\circ} \mathrm{C}$ and $40 \mathrm{~atm}$. This temperature is already higher than the highest operating temperature permitted by the existing design criteria for nuclear apparatuses. In addition, the fact that the heat exchange must be performed in high temperature, high pressure helium atmosphere, itself hitherto unknown service environment, makes it impossible to design this unit with satisfactory margin of safety on the existing design criteria.

Therefore, an entirely new set of design criteria must be prepared and tested in a large, quasi-real size high-temperature helium test loop. For designing and construction of this high-temperature helium test loop, following basic researches have been made:

1) Establishment of a design method for the hightemperature heat exchanger

2) Structural model test

3) Research on vibration characteristics

4) Research on augmentation of heat transfer

5) Establishment of monitoring and detection system for the high-temperature heat ex- 


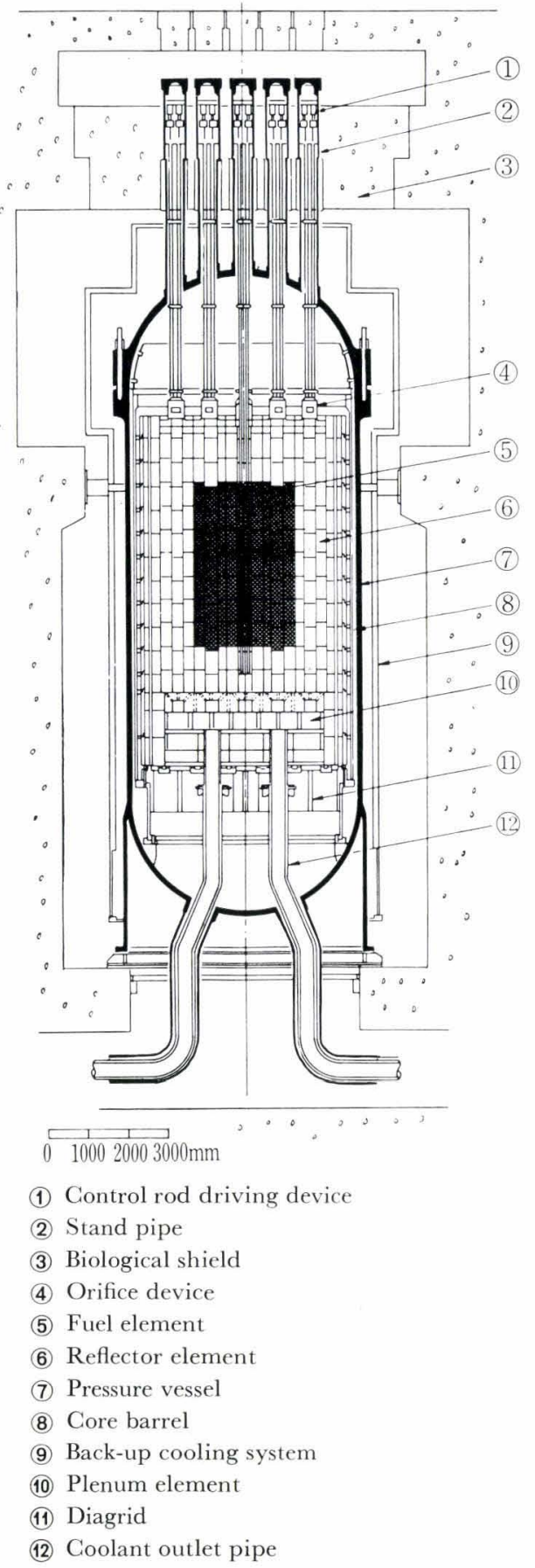

Fig. 6. Design concept of the multi-purpose high temperature gas-cooled experimental reactor

changer

6) Development of a helium circulator

7) Development of a $3 \mathrm{MW}$ helium heater

8) Development of a thermal insulation system in the very high temperature region

9) Research on the hydrogen permeation phenomenon

10) Development of an emergency shut-off valve and a bypass valve

11) Development of a helium purification system to remove hydrogen and other impurities

12) Research on a system for the continuous measurement of hydrogen and the analysis of impurities in helium

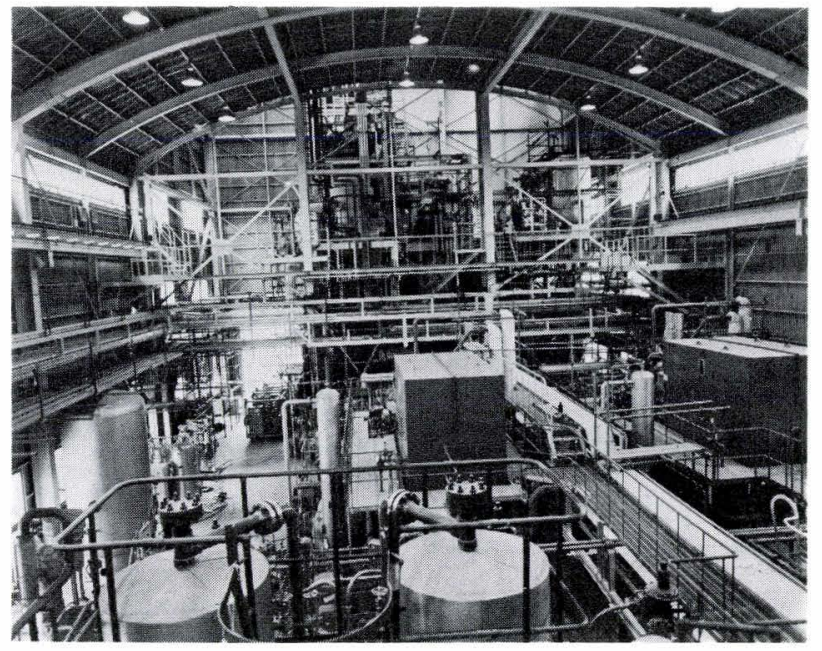

Photo. 1. High-temperature helium test loop

Table 2. Design data of high temperature heat exchanger

\begin{tabular}{l|lr}
\multicolumn{1}{c}{ Shell } & $\begin{array}{l}\text { Outside diameter } \\
\text { Height }\end{array}$ & $\begin{array}{r}1560 \mathrm{~mm} \\
13000 \mathrm{~mm}\end{array}$ \\
\cline { 1 - 2 } $\begin{array}{l}\text { Heat Transfer } \\
\text { Tube }\end{array}$ & $\begin{array}{l}\text { Size } 25.4 \mathrm{~mm} \mathrm{O} \text { O. } \times 4.0 \mathrm{~mm} \text { thick } \\
\text { Number } 30\end{array}$ \\
\hline $\begin{array}{l}\text { Temperature } \\
\text { Entering }\end{array}$ & $\begin{array}{l}\text { Shell side } \\
\text { Tube side }\end{array}$ & $1000^{\circ} \mathrm{C}$ \\
\hline $\begin{array}{l}\text { Temperature } \\
\text { Leaving }\end{array}$ & Shell side & $327^{\circ} \mathrm{C}$ \\
\hline & Tube side & $379^{\circ} \mathrm{C}$ \\
$925^{\circ} \mathrm{C}$
\end{tabular}

13) Sliding wear and fretting wear tests of metallic materials.

These efforts have culminated in a 1.5 MW hightemperature helium test loop shown in Photo. 1. The loop comprises an helium purification unit (foreground), a pair of helium circulators, one for the primary line and the other for the secondary (middle ground), a 1.5 MW heat exchanger, a $3 \mathrm{MWt}$ helium heater, a steam heater, and a steam generator (background), and completes with control-cum-data processing system and auxiliary units, some of which are installed outside this housing. Table 2 shows the elementary data on the high-temperature heat exchanger. Operation of this test loop has commenced October, 1978.

\section{Heat Resistant Superalloy}

Primary importance is attached to the creep rupture strength which is to be no lower than $1 \mathrm{~kg} / \mathrm{mm}^{2}$ at $50000 \mathrm{hr}$ (ultimately $100000 \mathrm{hr}$ ) in a helium atmosphere at $1000^{\circ} \mathrm{C}$. New superalloys for manufacturing pipes with $25 \mathrm{~mm}$ O.D., $15 \mathrm{~mm} \mathrm{I.D.} \mathrm{and} \mathrm{over}$ $7 \mathrm{~m}$ in length are being developed.

Table $3^{6)}$ shows an estimation of the creep rupture strength of conventional wrought alloys in air at $1000^{\circ} \mathrm{C}$. It is impossible to find any alloys having the necessary strength mentioned above. In addition, it has been observed in some cases that the creep rupture strength of an alloy in helium atmosphere is lower than that in air. Therefore, it has been 
Table 3. Estimated creep rupture strength of superalloys (by Larson-Miller method)

\begin{tabular}{c|cc}
\hline \multirow{2}{*}{ Alloy } & \multicolumn{2}{|c}{ Creep rupture strength $\left(\mathrm{kg} / \mathrm{mm}^{2}\right)$} \\
& $10000 \mathrm{hr}$ & $100000 \mathrm{hr}$ \\
\hline Incoloy 800 & 0.72 & 0.45 \\
Incoloy 807 & 0.55 & - \\
Inconel 617 & 1.05 & 0.60 \\
Inconel 625 & 0.82 & 0.52 \\
Hastelloy X & 0.82 & 0.48
\end{tabular}

judged that to manufacture heat transfer pipes using existing alloys is difficult, to say the least.

Thereupon, since 1973, eleven new alloys have been proposed, of which several have already been omitted from further development because the required creep rupture strength could not be obtained in trial manufacturing and various tests. Among the proposed alloys, details have been made public on the following types:

1) $\left.0.05 \mathrm{C}-16 \mathrm{Cr}-20 \mathrm{~W}-30 \mathrm{Co}-\mathrm{Ni}^{7}\right)$

2) $\left.0.03 \mathrm{C}-23 \mathrm{Cr}-18 \mathrm{~W}-\mathrm{Ni}^{8}\right)$

3) $\left.0.06 \mathrm{C}-18 \mathrm{Cr}-15 \mathrm{~W}-\mathrm{Ni}^{9}\right)$

4) $0.03 \mathrm{C}-15 \mathrm{Cr}-25 \mathrm{~W}-\mathrm{Ni}^{10}$

5) $0.03 \mathrm{C}-27.5 \mathrm{Cr}-5 \mathrm{~W}-5 \mathrm{Mo}-\mathrm{Ni}^{11}$

6) $0.06 \mathrm{C}-20 \mathrm{Cr}-20 \mathrm{~W}-\mathrm{Ni}^{12}$ )

Hydrogen permeation tests as well as creep rupture and corrosion tests in various atmospheres are being performed at the National Research Institute for Metals.

\section{High-temperature Heat Insulating Materials}

The characteristics of heat insulating materials in atmospheres of high-temperature helium, steam or reducing gas are different from those in air. It is necessary, therefore, to develop heat insulating materials which can maintain stable characteristics for a long time in these atmospheres, particularly in a high-temperature helium atmosphere. In this project, blocks made of fused silica refractories and $\mathrm{Al}_{2} \mathrm{O}_{3}-\mathrm{SiO}_{2}$ in fibrous shape have been selected as the materials for development. Research on manufacturing methods as well as characteristics tests of the materials manufactured in trial are in progress. The aim of the research and development is to improve the insulating performance of these materials in helium gas at over $1000^{\circ} \mathrm{C}$ and at $40 \mathrm{~atm}$ and in a reducing gas or steam atmosphere at approximately $900^{\circ} \mathrm{C}$. Besides the obvious requirement that no substance detrimental to the operation must be discharged, any change in properties occurring through a 100000 hr service must be:

1) Increase in thermal conductivity: less than $10 \%$

2) Increase in gas permeability: less than 10\%

3) Shrinkage: less than $0.1 \%$

4) Resiliency from $50 \%$ compression (for fibrous material): greater than $20 \%$.

Fused silica refractories are being studied with the accent on restraining devitrification and minimizing shrinkage. Restraining of devitrification will present

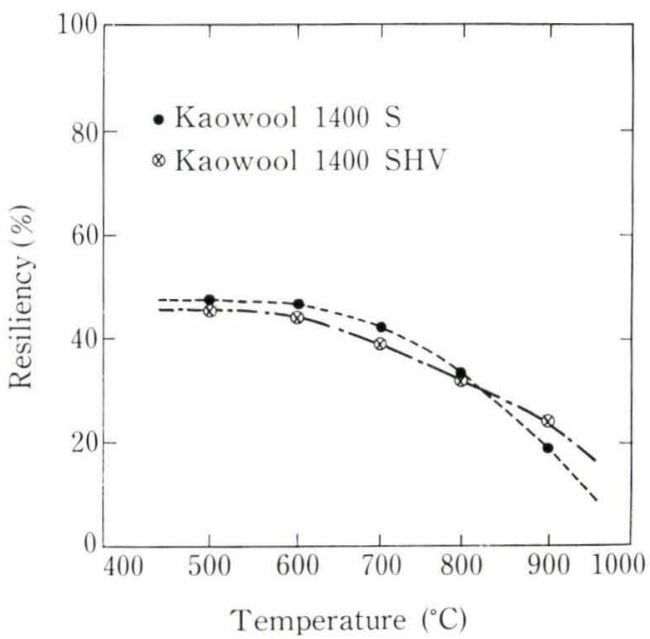

Fig. 7. Resiliency of newly developed insulators as heated for $20000 \mathrm{hr}$ in helium

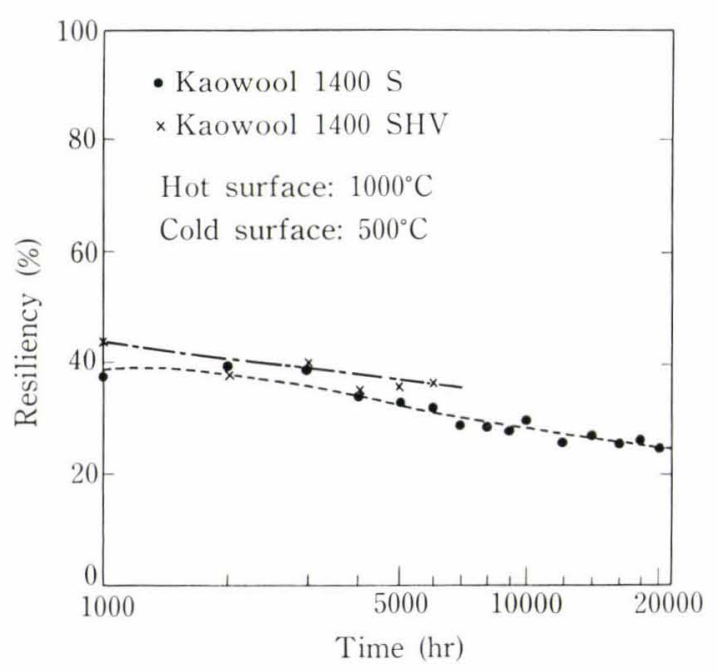

Fig. 8. Resiliency under a thermal gradient

no problem since some materials show no evidence of devitrification after heat treating for more than $27000 \mathrm{hr}$ at $1000^{\circ} \mathrm{C}$ in a helium atmosphere. Also, holding shrinkage to within the specified limits seems possible through the selection of particle size, baking temperature and time. It appears also possible to achieve the required thermal conductivity and permeability at $1000^{\circ} \mathrm{C}$ in helium atmosphere.

The $\mathrm{Al}_{2} \mathrm{O}_{3}-\mathrm{SiO}_{2}$ fibrous insulator are being studied with the emphasis on improving resiliency. Figure 7 shows the result of a resiliency test conducted for $20000 \mathrm{hr}$ keeping the temperature uniform through the sample. Apparently, it is difficult to obtain the target value of $20 \%$ resiliency at temperatures over $900^{\circ} \mathrm{C}$, but, since a temperature gradient always exists through the heat insulating material, the uniform temperature tests are too severe. Actually, from the results presented in Fig. 8, it seems possible to achieve the target value given a temperature gradient of $1000^{\circ} \mathrm{C}$ at the hot surface and $500^{\circ} \mathrm{C}$ at the cold surface.

In addition, several heat insulating structures combining the fused silica refractories and the $\mathrm{Al}_{2} \mathrm{O}_{3}-$ 
$\mathrm{SiO}_{2}$ fibrous materials are being examined together with their fabrication methods. Photograph 2 shows the test apparatus of the structure to determine the heat insulating characteristics in helium atmosphere at $1000^{\circ} \mathrm{C}$ and $40 \mathrm{~atm}$.

\section{Reducing Gas Production Unit}

As mentioned earlier, Japan, a country having little fossil fuel resources, has a very limited option to select raw materials for the reducing gas production. The selection of vacuum residual oil, a byproduct of oil refining, is significant because it is a mere remainder of the costly imported oil.

For shaft furnaces, the desired characteristics of the reducing gas are $\mathrm{H}_{2} /\left(\mathrm{H}_{2}+\mathrm{CO}\right)>0.5, \quad\left(\mathrm{H}_{2} \mathrm{O}+\right.$ $\left.\mathrm{CO}_{2}\right) /\left(\mathrm{H}_{2}+\mathrm{CO}\right)<0.1, \mathrm{CH}_{4}<3 \%$ and a temperature of between $800^{\circ}$ and $850^{\circ} \mathrm{C}$. In addition, since these shaft furnaces can utilize only $30 \%$ of the resident reducing gas, re-cycling of the top gas is a necessity.

Steam raised to about $800^{\circ} \mathrm{C}$ with nuclear heat is used to crack the vacuum residual oil. The reducing gas is produced through the steam reforming process of light hydrocarbons with nuclear heat and through gasifying pitch with high-temperature steam and oxygen. A low-sulfur fuel oil is produced by converting heavy oil into hydrogen followed by a desulfurizing step. Since the steam cracking process of vacuum residual oil and hydrodesulphurization process of heavy oil are already established and have been in operation commercially, it was determined in this project to develop a heat exchange type steam reformer and a pitch gasifying unit. A concentrated effort is being made to develop a steam reformer which produces reducing gas at $850^{\circ} \mathrm{C}$ by utilizing helium gas as the heating fluid, reforming light hydrocarbons with a suitable catalyst. In 1974, the design stage began on a selected model of the steam reformer. The basic tests necessary for this design, such as material and prototype tests, were carried out. Further, a testing unit was installed to obtain information concerning heat transfer characteristics and pressure losses. Also, basic tests concerning the chemical reactions are being conducted. Based on the results of these tests, a test plant of a steam reformer treating $100 \mathrm{~kg} / \mathrm{hr}$ of naphtha was built. Photograph 3 illustrates the test plant, which is in operation since June, 1978, and Table 4 shows the elementary data of the plant.

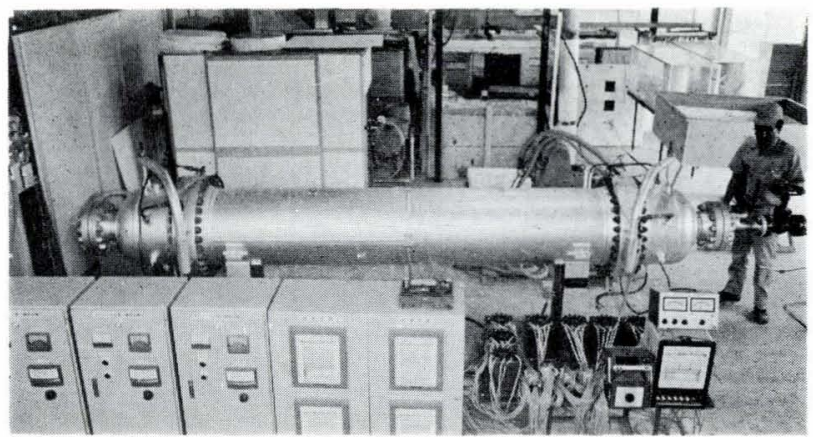

Photo. 2. Thermal barrier testing equipment
The unit for gasifying pitch converts super-heavy hydrocarbons containing extremely small percentage of hydrogen into coke. The reducing gas is produced by gasifying this coke with the water-gas reaction. On the basis of the tests conducted with a microreactor of $400 \mathrm{~g} / \mathrm{hr}$ capacity and a bench scale reactor of $1 \mathrm{~kg} / \mathrm{hr}$ capacity, a test plant to treat $200 \mathrm{~kg} / \mathrm{hr}$ of pitch is being constructed. This test plant is to be completed in September, 1978, and will be capable of generating from $1 \mathrm{t}$ of vacuum residual oil $0.5 \mathrm{t}$ of low sulfur fuel oil as well as reducing gas enough to produce $3 \mathrm{t}$ of reduced iron.

\section{Reduced Iron Production System}

During the planning stage, both a shaft furnace and a fluidized bed reactor were in operation, each producing about $1000 \mathrm{t} /$ day of reduced iron using reducing gas. After comparing and considering these two systems, however, the shaft furnace system was selected for this nuclear steelmaking project. High pressure operation was required for the shaft furnace to be compatible with other units in the total nuclear steelmaking system, but at that time there was no instance of a shaft furnace operating at such pres-

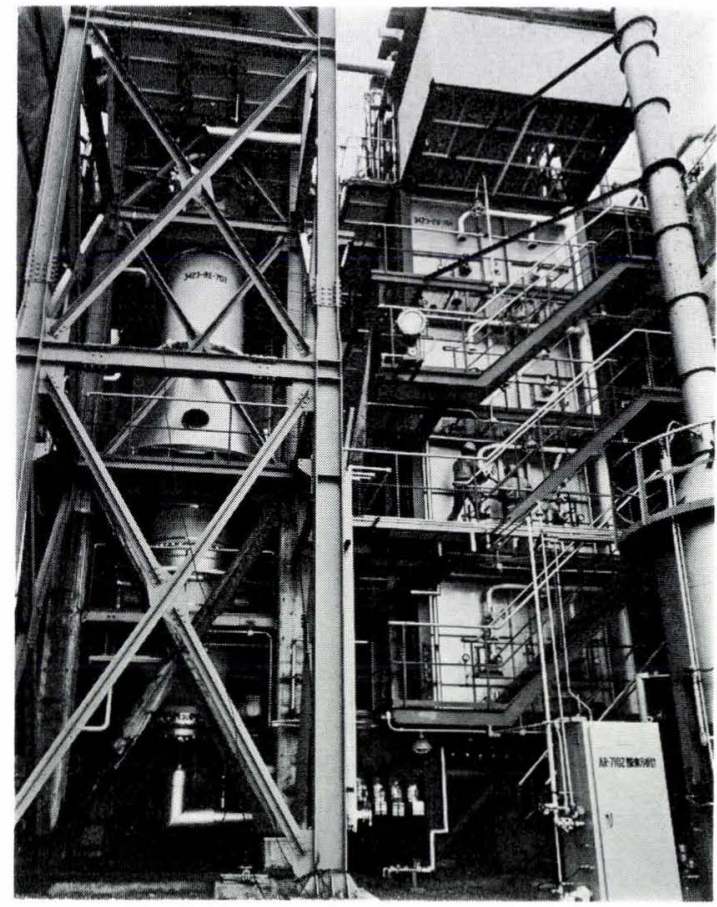

Photo. 3. Heat exchange type steam reformer test plant

Table 4. Design data of heat exchange type steam refromer

\begin{tabular}{l|lr}
\multicolumn{1}{|c|}{ Shell } & $\begin{array}{l}\text { Outside diameter } \\
\text { Height }\end{array}$ & $1580 \mathrm{~mm}$ \\
\hline \multirow{2}{*}{ Tube } & O. D. & $72 \mathrm{~mm}$ \\
& I. D. & $50 \mathrm{~mm}$ \\
& Effective height & $8760 \mathrm{~mm}$ \\
& Number & 8
\end{tabular}

Capacity $\quad 100 \mathrm{~kg} / \mathrm{hr}$ (Naphtha) 
sures. ${ }^{*}$ Therefore the problems considered were the improvement of productivity and energy efficiency resulting from the application of high pressure and the determination of the optimum range of the reducing gas composition. Also, the development of new equipment to transfer solids and gases into and out of the shaft furnace and to control the distribution of gas flow was required.

Iron ore reduction experiments ${ }^{13)}$ were conducted at atmospheric pressure for various kinds of pellets with the JIS reducing apparatus (JIS M8713). Valuable data were obtained on the effects of temperature and of the $\mathrm{CO}_{2}, \mathrm{H}_{2} \mathrm{O}$ and $\mathrm{CH}_{4}$ contents on the reduction rate and reduction degree attained after a specified time. Other investigations completed were on the effect of the $\mathrm{CO}: \mathrm{H}_{2}$ ratio in the reducing gas, carbon deposition, pellet degradation and the strength of the reduced iron.

In order to further clarify the reducing reaction of iron ore at high pressures, a shaft furnace simulator, as shown in Fig. 9, was constructed, and experiments were initiated in February, 1975. With this equipment, the specimens were subjected to the same history of thermal and reducing conditions encountered by an iron ore pellet charged into the shaft furnace. By following the behavior of the specimen as it is charged into the top, converted into reduced iron and discharged out the bottom, a simulation model was established. The diameter of the reaction pipe was $120 \mathrm{~mm}$, and the specimen composed a fixed layer weighing 3 to $5 \mathrm{~kg}$. The maximum pressure and the highest temperature of the reducing gas were $15 \mathrm{~atm}$ and $1000^{\circ} \mathrm{C}$, respectively, and the composition was freely changeable. By utilizing this equipment, the reduction rate, the rate of formation and decomposition of methane, and the carbon deposition reaction were examined. Also, data for optimizing the reducing gas conditions in the shaft furnace were obtained. The principal results were as follows:

(1) The pressure increase in the shaft furnace caused carbon deposition as well as the violent formation of methane.

(2) The desired conditions to prevent carbon deposition were in the low pressure side of the shaft furnace operation.

(3) The effects of composition, pressure and degree of oxidation of the reducing gas on the reducing time were clarified.

(4) Reducing gas conditions that promise stable operation of the shaft furnace and efficient productivity were established.

(5) A high precision mathematical models for simulation purposes was developed making it possible to estimate the shaft furnace capacity and the quantity of reducing gas needed.

As for auxiliary equipments for the high pressure furnace, experiments were conducted with several cold models. Out of those studies, a charging and discharging system, shown in Photo. 4, a seal valve and a stop valve, both special for this system, were developed. Also, a study on gas flow was conducted in preparation for scaling-up of the shaft furnace and for selecting the furnace configuration.

To develop a system to recover heat from the reduced pellets, experiments and simulation model exercises were carried out. The effect of changing the distance between the blast and suction nozzles on the gas flow pattern was investigated. Also, the number and diameter of the nozzles and the shaft furnace diameter were varied to clarify their effects on the gas flow.

On the basis of these results, a $2000 \mathrm{t} /$ day shaft furnace that is compatible with the projected experi-

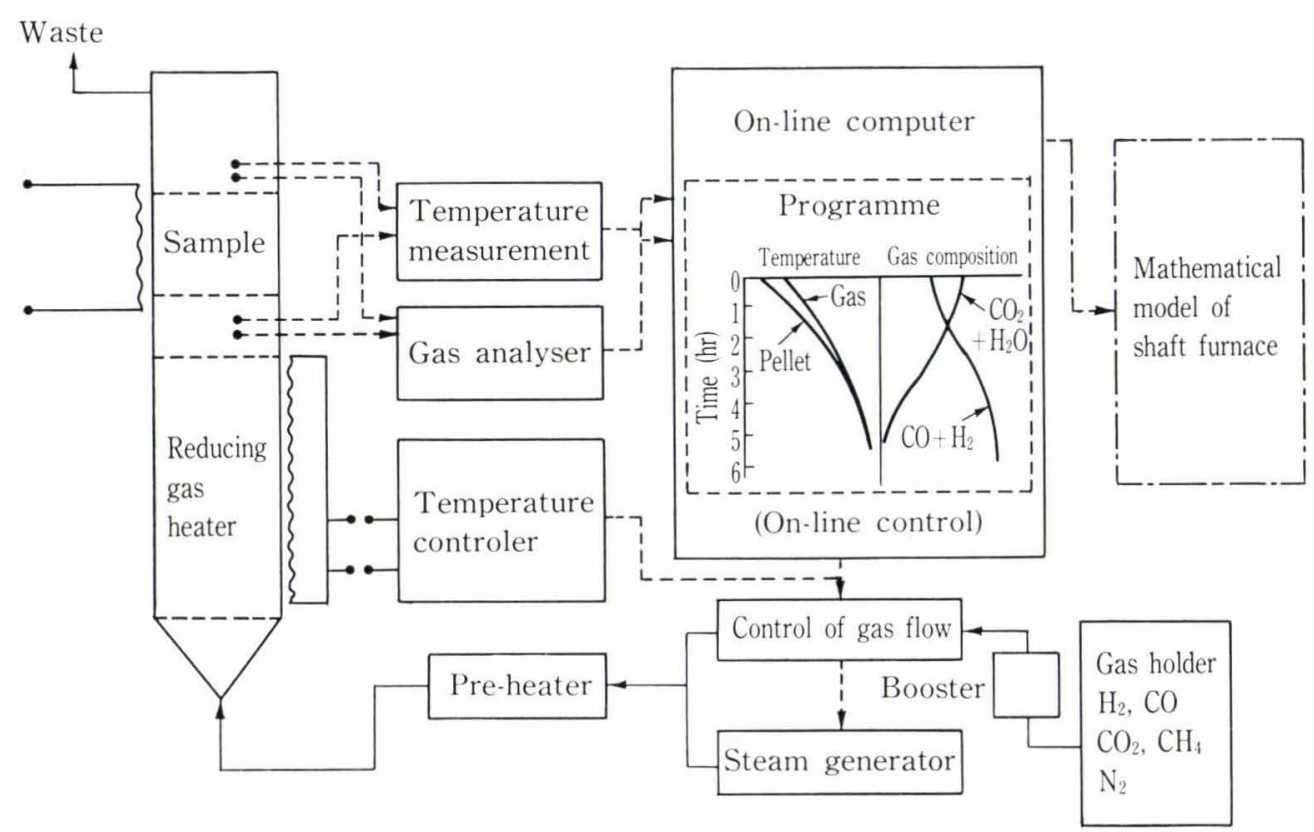

Fig. 9. Basic concept of the shaft furnace simulator

* Subsequently, Hirohata Works, Nippon Steel Corp., operated a $500 \mathrm{t}$ shaft furnace with a top pressure of $4.5 \mathrm{~kg} / \mathrm{cm}^{2} \mathrm{G}$. 
mental HTGR pilot plant is at the conceptual design stage.

\section{Total System for Nuclear Steelmaking}

The nuclear steelmaking system incorporating a multi-purpose, $50 \mathrm{MW}_{\mathrm{th}}$ experimental HTGR has been designated the FM-50 system. The aim of the study is to complete a conceptual design of this FM50 system. The program is in progress in accordance with the following procedures to be completed in 1979:

1) Formulation of a steady-state model for each subsystem

2) Formulation of a steady-state simulation model for the entire system by connecting together the subsystem steady-state models

3) Calculation of material balance and heat balance for various process patterns, and selection of a nuclear steelmaking process pattern

4) Preparation of equipments for the selected process pattern, and examination of the layout and

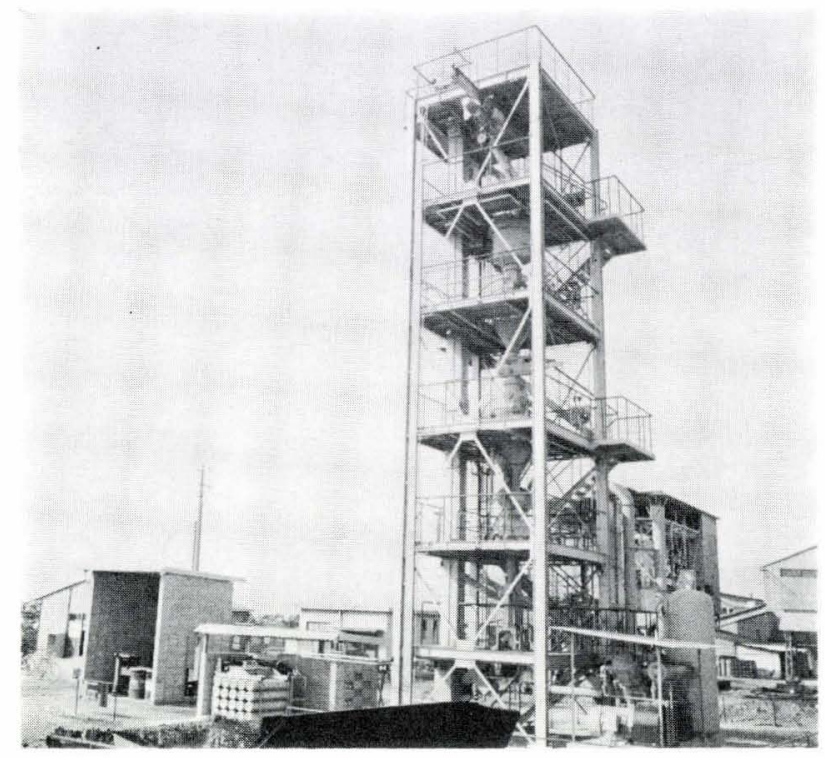

Photo. 4. Cold model for charging and discharging system of shaft furnace utilities

5) Formulation of a system dynamic model to examine and evaluate safety and process control

6) Designing of instrumentation and control schemes

7) Determination of the experimentation plan

8) System safety analysis.

In determining the FM-50 system pattern, free use was made of the steady-state simulation model (SNAP), which had already been developed. Figure 10 shows an example of the heat balance calculated with SNAP for the selected pattern. It is to be noted that no inclusion of a power generating system in the FM-50 system is considered here.

Out of the SNAP, a simulation model to analyze dynamic characteristics (DYNAP) has been developed for grasping the dynamic behavior of the system, for designing the control system and for carrying out accident analysis. As an example, Fig. 11 shows the changes in temperature of the helium leaving the steam reformer and in the temperature and flow rate of the reducing gas in the reformer when the inlet helium temperature is suddenly dropped by $20^{\circ} \mathrm{C}$.

The next stage is the designing and construction of an FM-50 system pilot plant. It is expected that this pilot plant will be in operation in or around 1986 with an experimental HTGR also in operation.

\section{Conclusion}

It appears as if the world economy will continue to be subjected to the impacts of fluctuation of both price and supply of oil resources, but coal and nuclear energy will enervate the effect. Although the nuclear energy has hitherto been understood as meaning solely the power generation, it is highly conceivable that one may expect a great deal in the extensive utilization of nuclear heat as process heat. In preparation for future energy crises, it is submitted that development under mutual cooperation, both international and interdisciplinary, of high-temperature gas-cooled reactors not only for the steelmaking but also for other industries and utilities should be intensified ever more.

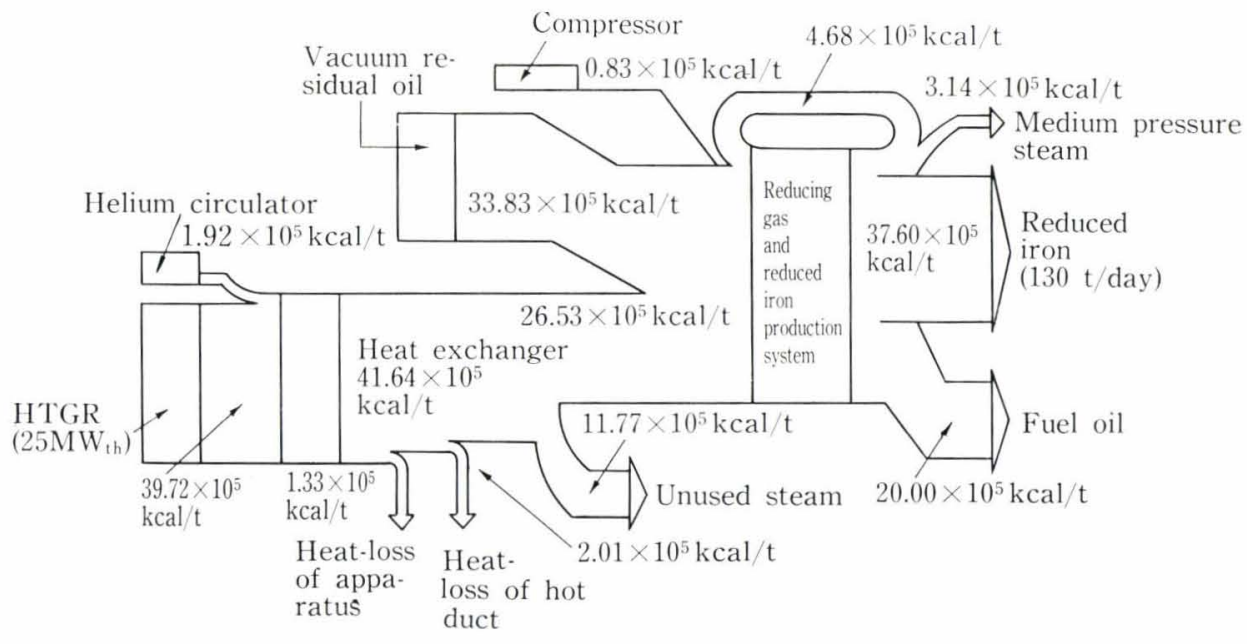

Fig. 10. Heat balance of FM-50 system 


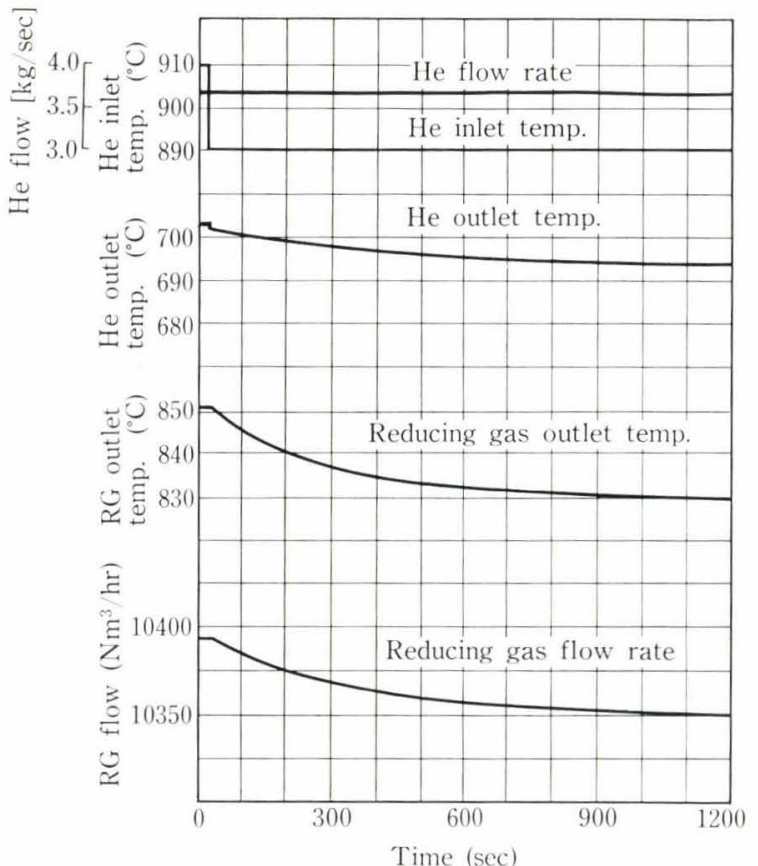

Fig. 11. Response of steam reformer to secondary helium inlet temperature change (Secondary helium inlet temp. $-20^{\circ} \mathrm{C}$ step change)

\section{REFERENCES}

1) R. S. Barnes: Iron Steel Eng., 53 (1976), 5, 53.

2) D. J. Blickwede: Iron Steel Eng., 53 (1976), 4, 38.

3) H. Juntgen and K. H. van Heek: Nuclear Eng. and Design, 34 (1975), 1, 59.

4) L. Schrader, W. Schtrauss and H. Teggers: Nuclear Eng. and Design, 34 (1975), 1, 51.

5) Status of Research and Development on Multi-purpose HTGR, ed. by Japan Atomic Energy Research Institute, (1976).

6) Second Report of the 122nd-123rd Joint Committee on Heat Resisting Materials, The Japan Society for the Promotion of Science, (1975).

7) R. Watanabe, Y. Chiba and T. Kuno: Tetsu-to-Hagané, 61 (1975), 2405.

8) R. Watanabe and Y. Chiba: Tetsu-to-Hagané, 63 (1977), 118.

9) Y. Hosoi, A. Shinoda, Y. Tsuchida, S. Sekino, N. Sakakibara and H. Honma: Tetsu-to-Hagané, 62 (1976), S803.

10) S. Ohta, K. Aota, T. Motoda and T. Honjo: Tetsu-toHagané, 62 (1976), S802.

11) T. Yukitoshi, K. Yoshikawa and T. Sawaragi: Report of the 123rd Committee on Heat Resisting Metals and Alloys, The Japan Society for the Promotion of Science, Rep. No. 18, (1977), 163.

12) T. Ohmura, Y. Sahira, A. Sakonooka and N. Yonezawa: Tetsu-to-Hagané, 61 (1975), S323.

13) A. Sasaki and K. Okabe: Tetsu-to-Hagané, 61 (1975), S3. 